\title{
How a Learning-Oriented Organizational Climate is Linked to Different Proactive Behaviors: The Role of Employee Resilience
}

\author{
Marjolein C. J. Caniëls ${ }^{1} \cdot$ Simone M. J. Baaten ${ }^{1}$
}

Accepted: 31 August 2018 / Published online: 6 September 2018

(c) The Author(s) 2018

\begin{abstract}
This study develops and tests a model of the relationship between a learning-oriented organizational climate, employee individual resilience and three broad categories of proactive behaviors, i.e. proactive work behavior, proactive strategic behavior and proactive person-environment fit behavior. The study tests a mediation model. Cross-sectional data was gathered from 108 employees in four Dutch organizations. Results demonstrate that employee resilience mediates the relationships between a learning-oriented organizational climate and proactive work behaviors. By investigating three proactive behaviors, this study answers to the call for studies that empirically investigate multiple related proactive behaviors within one study design. This design sheds light on whether a learning-oriented organizational climate promotes certain proactive behaviors more than others.
\end{abstract}

Keywords Organizational learning $\cdot$ Proactivity $\cdot$ Resilience

\section{Introduction}

Employee resilience refers to bouncing back from challenges at work to come back better than before (Smith et al. 2008). Employee resilience can be seen as a trait variable that has state-like characteristics, as it is a personal disposition that can be developed over time, albeit slowly (see Xanthopoulou et al. 2009; Luthans 2002). In other words, it is a malleable personal resource (Xanthopoulou et al. 2009). Studies show that resilient employees are better in achieving various organizational goals such as job performance and organizational commitment (Youssef and Luthans 2007; Meneghel et al. 2016; Wang et al. 2017). When employees are able to cope with failure and setbacks they are likely to perform well and show organizational commitment even under conditions of stress and change (Coutu 2002). Hence, it is in the interest of organizations

Marjolein C. J. Caniëls

Marjolein.Caniels@ou.nl

Simone M. J. Baaten

simonebaaten@gmail.com

1 Faculty of Management, Science and Technology, Open University of the Netherlands, P.O.

Box 2960, 6401 DL Heerlen, The Netherlands 
to identify organizational factors that can help employees build resilience (Kuntz et al. $2017 \mathrm{a}, \mathrm{b}$ ). A growing body of research suggests that learning from experience and failure is positively associated with resilience (Huang and Luthans 2015; Vogus and Sutcliffe 2007). For example, studies in the field of organizational learning have suggested that an organizational climate, whose continuous improvement mechanisms include the open discussion of problems by employees, may be positively related to work engagement and resilience in employees (Baer and Frese 2003; Van Dyck et al. 2005). It has been shown that a positive organizational approach to errors and failures potentially has long-term positive consequences, such as learning, innovation, and resilience (Sitkin 1992; Madsen and Desai 2010). Such a constructive organizational approach to errors and failure can be conceived of as an organizational resource that stimulates resilience in employees (Meneghel et al. 2016).

Employee resilience is an antecedent to organizational outcome variables including job performance, job satisfaction and organizational commitment (Youssef and Luthans 2007; Meneghel et al. 2016), creativity (Huang and Luthans 2015), and work engagement (Mache et al. 2014). Until now only a few studies have investigated how resilience is related to career self-management behaviors, such as seeking developmental feedback (e.g. Chiaburu et al. 2006). In the present paper, we relate resilience to an important set of self-management behaviors, namely proactive behaviors. Proactive behavior, as opposed to passive behavior, is defined as "self-initiated, anticipatory action that aims to change and improve the situation or oneself" (Parker and Collins 2010, p. 635; Grant and Ashford 2008). Proactive behavior is focused on change and improvement (Bindl and Parker 2010, p. 15). This behavior requires that individuals are persistent (Frese and Fay 2001), regulate their efforts, and are not easily derailed by failure (Bindl and Parker 2010). The study in the present paper will investigate the degree in which a learning-oriented organizational climate will stimulate proactive behaviors of employees via employee resilience.

From a theoretical perspective, this study contributes to the literature in several important ways. It increases current understanding about the benefits of a learning-oriented organizational approach for positive individual outcomes. Specifically, we contribute to the existing literature on organizational learning climate (Putz et al. 2012; Van Dyck et al. 2005) and proactive behaviors (Parker and Collins 2010), by uncovering an important mediating mechanism, i.e. employee resilience. Resiliency is gaining increased attention in current management literature and there are recent calls for more understanding of resilience in the context of organizational behavior (Britt et al. 2016; Kossek and Perrigino 2016; Rothstein et al. 2016). However, the relationship between a learning-oriented organizational climate and employee resilience is still poorly understood. Yet, fostering employee resilience is an important topic, because resilience can help employees to recover from daily setbacks at work (Britt et al. 2016) and it may induce self-management behaviors.

Furthermore, this study highlights the positive relationship of a learning-oriented organizational climate with proactive work behaviors. It addresses the extent in which organizations with a greater capacity to learn from failures are better at capitalizing the benefits of resilience, in terms of proactive behaviors. Hereby, the study responds to requests for evidence about consequences of proactive behavior for employees' well-being and specifically resilience (Liu et al. 2016). By designing a model that includes three proactive behaviors, this study answers to calls for studies that empirically investigate multiple related proactive behaviors within one study design (Parker and Collins 2010; Tornau and Frese 2013). The study sheds light on whether employee resilience is more effective in promoting certain proactive behaviors than others. 


\subsection{Theoretical Foundation and Hypotheses}

Resilience is often associated with the ability to learn from and adapt to changing circumstances (Bhamra et al. 2011). Resilient individuals recover from setbacks and expediently adjust themselves to a changed environment (Bhamra et al. 2011). Resilience at work refers to an employee's capability to continuously adapt positively to adverse conditions (London 1993; Von Eisenhart Rothe et al. 2013) and to use work resources to ensure ongoing development and growth at work (Kuntz et al. 2017a, b). Yet, much remains unknown about factors that build resilience at work (Britt et al. 2016; Kossek and Perrigino 2016; Rothstein et al. 2016).

We follow Xanthopoulou et al. (2009) and Luthans (2002) in our conceptualization of resilience as a trait variable that has state-like characteristics, such as determination, humor, and resourcefulness (Von Eisenhart Rothe et al. 2013). Resilience can be conceptualized as a personal resource that supports adaptation to better state. A growing body of research has suggested that learning from experience and failure, and hence a learning-oriented organizational climate, is positively associated with resilience (Huang and Luthans 2015; Vogus and Sutcliffe 2007).

Organizational learning from errors refers to the ability of an organization and its employees to adapt over time in reaction to challenges (Putz et al. 2012). A learning-oriented organizational climate emphasizes the importance of consciously dealing with errors and failures in order to learn from them (Putz et al. 2012; Van Dyck et al. 2005). In such an organizational climate, employees perceive that the organization learns from experiences, which enables it to adapt when facing challenges in the future. Learning emphasizes positive adaptation and involves managing the trade-off between exploring new challenges and exploiting existing competencies (Sutcliffe and Vogus 2003, p. 104). In organizations that expose a learning-oriented organizational climate, failure and mistakes are used as an input for improvement and not as a reason for punishment.

Recent studies have suggested a relationship between an organizational learning climate and resilience on an organizational level (Vogus and Sutcliffe 2007), and an individual level (Huang and Luthans 2015). For example, Vogus and Sutcliffe (2007) argue that, on an organizational level, learning is an input to resilience: "Resilient organizations seem to employ a superior brand of learning, but more research is needed to understand the character of this learning and what specific resources give rise to it" (p. 3421). This argument is in line with a broad array of studies that show that the work environment of employees is crucial with regard to various outcome variables at the individual level, such as job satisfaction, job performance and resilience (Hirst et al. 2009; Griffin 2007). Failing plans and making mistakes can evoke negative emotions in employees, such as feeling inadequate, anxious and shameful (Zhao 2011; Frese and Keith 2015). These feelings may have negative consequences for individual performance, as they draw attention away from the tasks at hand (Frese and Keith 2015). However, a learning-oriented organizational climate in which failures and mistakes are positively framed (i.e. as opportunities to learn and as a normal part of learning) has been shown to help employees to control negative emotions, switch from a blaming mindset to a learning-oriented mindset, and remain concentrated on their work (Heimbeck et al. 2003; Frese and Keith 2015). In such an environment, employees experience psychological safety, i.e. a shared belief that it is safe to take risks and voice an opinion (Edmondson 1999).

In line with prior research about the organizational benefits of psychological safety (e.g. Edmondson 1999), we argue that employees who perceive a learning-oriented 
organizational climate will expose a high level of resilience. When there is a learning-oriented organizational climate within an organization, employees will not be afraid to make mistakes. On the contrary, they are likely to feel free to take the initiative to experiment, take risks, and propose creative ideas. Over time, this positive attitude towards experimentation and the accompanying amount of misses and errors will build resilience, because employees get used to a certain amount of setbacks. In all experimentation, some plans will work out and lead to improvements, but the majority of plans are likely to fail to work out in practice (Simonton 1984; Tesluk et al. 1997). When employees take risks more often, it is likely that a larger amount of miscalculations and misconceptions happen. As a certain ratio of ideas that are put to the test will simply fail, trying out many ideas means a high amount of failures. Many ideas will not work out in a desirable way. However, in a learning-oriented organizational climate employees will have experienced over time that failures and errors will induce adjustments to the original idea or behavior (Sitkin 1992). These adjustments may turn out to be improvements or at least generate progress, which would not have happened without the initial trial and error. Hence, employees who perceive a learning climate that encourages experimentation are used to making mistakes and having negative experiences. By feeling free to experiment, many adjustments to organizational procedures will be put to the test. All this time, employees are aware that they have to expect a certain amount of failure. Therefore, they will not feel easily discouraged or distressed by negative results. Over time, this process of being exposed to failure and negative experiences accumulates into building endurance and resilience (Griffin et al. 2007), and employees develop the ability to successfully cope with setbacks (Wagnild and Young 1993). If failing is not punished within the organization but rather seen as an opportunity for improvement, as is the case in a learning-oriented organizational climate, employees will be less prone to feelings of inadequacy, and hence be resilient. In this line, we hypothesize:

Hypothesis 1 The degree in which employees perceive a learning-oriented organizational climate is positively related to employee resilience.

Employees who work in an organization that provides a learning climate, in which errors and failures are addressed by constructive ideas for adjustment rather than punishment, are likely to take initiative and propose new ideas. Employee resilience is likely to mediate this process, because a learning climate builds resilience in employees, which will in turn feel encouraged to shape their own future and hence be proactive in their behavior. In other words, a learning-oriented organizational climate will stimulate proactivity in employees via employee resilience. This reasoning draws on social cognitive theory (SCT), which suggests that it is of key importance to human agency to be able to manage one's own functioning and to exercise control over the events that have an impact on one's life (Bandura 1986).

An influential study of Parker and Collins (2010) identified three categories of proactive behaviors: (1) proactive work behavior, (2) proactive strategic behavior, and (3) proactive person-environment fit (P-E fit) behavior. Proactive work behavior is aimed at improving the organization's internal work processes. This behavior includes taking charge (Morrison and Phelps 1999), voice (Van Dyne and LePine 1998), implementing new strategies (Scott and Bruce 1994), and problem prevention (Frese and Fay 2001; Parker and Collins 2010; Bindl and Parker 2010). Proactive strategic behavior focuses on the improvement of the organization's fit with its external environment. This behavior manifests itself in actions such as issue-selling (Ashford et al. 1998), and strategically scanning the external 
environment to anticipate new developments and possibilities for creating competitive advantage (Parker and Collins 2010; Bindl and Parker 2010). Finally, proactive P-E fit behavior is targeted at enhancing a fit between one self and the organization. This behavior includes feedback seeking (Ashford and Cummings 1983) and career development negotiations (Parker and Collins 2010; Bindl and Parker 2010).

We argue that employees may act proactively when they experience a learning-oriented organizational climate, in which management and colleagues are supportive, so that one does not have to be afraid of failing and making mistakes, and in which they have built resilience against setbacks. For example, in a learning-oriented organizational climate employees have open discussions about things that have gone wrong in day-to-day work and co-workers will help each other to avoid and correct errors. These practices will build individual employees' resilience because they confront employees with their own mistakes (as well as those made by co-workers) but also offer coping strategies. In turn, employee resilience generates awareness that one can manage and control set-backs at work. Resilient employees will feel comfortable by exercising proactive behaviors that further shape their work, even when certain risks may be included. For instance, a resilient employee may expose voice behavior by speaking up with new ideas or changes in procedures that could minimize mistakes (being an example of proactive work behavior), because in a learning-oriented organizational climate the employee perceives that this behavior will be valued. In such an environment the employee is less afraid that being critical at current practices will be punished by a leader or co-workers. Furthermore, being resilient will encourage an employee to engage into a critical discussion about current practices. Similarly, a resilient employee may expose strategic scanning behavior for example by identifying long-term opportunities and threats for the organization (being an example of proactive strategic behavior), because in a learningoriented climate the organization will be open to ideas for continuous improvement. Being resilient facilitates this proactive strategic behavior, because the employee is aware that he/ she can cope with possible critical reactions to his/her observations. Furthermore, a resilient employee may expose feedback monitoring behavior for instance by seeking feedback from a supervisor about work performance (being an example of proactive person-environment fit behavior), because in a learning-oriented organizational climate the feedback will focus on behavior and activities of the employee and not on personality. Being resilient facilitates this proactive person-environment fit behavior, because resilient employees are able to deal with critique on their functioning. Hence, we hypothesize:

Hypothesis 2 Employee resilience is positively related to (a) proactive work behavior; (b) proactive strategic behavior; and (c) proactive person-environment fit behavior.

Hypothesis 3 Employee resilience will mediate the relationship between a learning-oriented organizational climate and (a) proactive work behavior; (b) proactive strategic behavior; and (c) proactive person-environment fit behavior.

\section{Method}

\subsection{Sample and Procedure}

The target respondents were employees from a convenience sample of four large Dutch organizations, including a governmental organization, two service organizations and a department store. Management of all participating organizations indicated to have a 
learning-oriented organizational climate. Data was gathered via an online questionnaire in three organizations and via paper and pencil in one organization. In total 1050 employees received the questionnaire. After 1 week a reminder was sent. The cover letter explained the relevance of the study and emphasized the anonymity and privacy of respondents. We ensured respondents that there were no right or wrong answers and that we were purely interested in their opinion. Respondents could stop answering questions at any time during the survey. We provided contact information of the research team, so that questions about the questionnaire or in response to the questionnaire could be dealt with. By starting the questionnaire, respondents were providing informed consent. In total 125 (11.9\%) questionnaires were sent back to the research team. After removing incomplete and inconsistent forms we were left with 108 (10.3\%) usable responses. Reasons for limited response were the length of the questionnaire and the fact that the need for anonymity limited the possibilities of increasing the rate of return. For instance, the requirement of anonymity made it impossible to send targeted reminders, provide a monetary incentive or use personalization, while all of these measures have been suggested by Dillman (2000) to increase response rates. Table 1 shows the characteristics of our sample.

Self-reported data were used, which may present a risk associated with common method bias. However, in the context of a study on individual resilience, the use of self-reports is warranted (Conway and Lance 2010; Kim et al. 2013). External raters may not be able to pick up on the subtleties of the inner world of an individual that determines their resilience at work. External raters are therefore usually relying on general impressions (Lance et al.

Table 1 Characteristics of the sample $(n=108)$

\begin{tabular}{lc}
\hline Characteristics of respondents & \% of sample \\
\hline Work experience in years & \\
$0-3$ years & 13.0 \\
4-5 years & 19.4 \\
6-10 years & 22.2 \\
11-20 years & 29.6 \\
More than 20 years & 15.7 \\
Gender & \\
Male & 53.7 \\
Female & 46.3 \\
Age in years & \\
Below 25 & 0.0 \\
25-35 & 26.9 \\
36-45 & 28.7 \\
46-55 & 25.9 \\
56-65 & 15.7 \\
Ebove 65 & 2.8 \\
Bacation level secondary education (high school) & \\
General level practical education & 9.3 \\
Bachelor level & 17.6 \\
Master level & 38.0 \\
Doctoral level & 30.6 \\
\hline
\end{tabular}


1994). Hence, we follow previous studies about proactivity (Parker and Collins 2010) and employee well-being (Frese and Zapf 1999), who argued that the most valid source of data is likely to be the job incumbent oneself.

Nevertheless, we undertook several procedural remedies throughout the study process to ward off possible bias. In our setup we closely followed suggestions by Podsakoff et al. (2003), Conway and Lance (2010), and Spector (2006), who recommended useful research strategies for curbing the risk of common method bias. First, we protected respondents' anonymity and asked respondents to answer the questions as honestly as possible to reduce respondents' evaluation apprehension bias as well as social desirability bias (Podsakoff et al. 2003). Also the fact that our model contains mediation effects, lowers the risk of respondents 'guessing' the desirable answers (Malhotra et al. 2006), and thereby reduces the risk for a common method variance biased pattern of responses.

\subsection{Measures}

Multiple-item scales, closely following previous studies, were used to measure each construct. Unless otherwise reported the construct variables were measured on seven-point Likert scales ranging from 1 (totally disagree) to 7 (totally agree). The employee survey covered the following construct variables.

\subsubsection{Employee Resilience}

An employee's capability to adapt positively to adverse conditions was measured using the eleven-item scale developed by Von Eisenhart Rothe et al. (2013). This scale assesses personal characteristics such as determination, humor, and resourcefulness. All these characteristics provide personal resources that support adaptation to better state. An example item is "I feel that I can handle many things at a time". The reliability of the scale was $\alpha=.88$.

\subsubsection{Learning-Oriented Organizational Climate}

Learning-oriented organizational climate was measured by adopting the sixteen-item measure from Putz et al. (2012). This measure assesses the employee's perception of actual organizational learning from errors in his/her direct work environment, i.e., his/her daily experiences with how is dealt with errors. An example item is "Our supervisor praises his/ her employees when they share their experiences in dealing with errors". The reliability of the scale was $\alpha=.92$.

\subsubsection{Proactive Behaviors}

We used Parker and Collins' (2010) proactivity scale to assess employee proactive behaviors. The higher-order category 'proactive work behaviors' (10 items in total) was composed of four proactive behaviors: 'taking charge' ( 2 items), 'voice' (3 items), 'individual innovation' (3 items), and 'problem prevention' ( 2 items). Three items were removed from the scale after executing a confirmatory factor analysis (CFA), namely "How frequently do you try to implement solutions to pressing organization problems?", "How frequently do you communicate your views about work issues to others in the workplace, even if your views differ and others disagree with you?", and "How frequently do you spend time 
planning how to prevent reoccurring problems?". An example item of the proactive work behavior scale is "How frequently do you try to bring about improved procedures in your workplace?". The higher-order category 'proactive strategic behaviors' (9 items in total) consisted of three proactive behaviors: 'strategic scanning' (3 items), 'issue selling credibility' ( 3 items), and 'issue selling willingness' ( 3 items). An example item is "How frequently do you actively scan the environment to see what is happening might affect your organization in the future?". Finally, the higher-order category "proactive person-environment fit behaviors' (5 items in total) incorporated 'feedback inquiry' ( 2 items), and 'feedback monitoring' (3 items). Parker and Collins (2010) also identified the subscales 'job change negotiation' ( 3 items) and 'career initiative' (3 items), but these are different in nature as they explicitly address a change in jobs. The CFA confirmed this notion and showed that the items of these factors had too low loadings to be included in the scale. A sample item of the proactive person-environment fit behaviors scale is "How frequently do you seek feedback from your supervisor about your work performance?". All higherorder structures yielded good internal reliability (respectively $\alpha=.88, \alpha=.92$, and $\alpha=.85$ ). We conducted a three-factor CFA to examine the distinctiveness of the three-factor model as proposed by Parker and Collins (2010). The three-factor model showed an acceptable model fit $\left(\chi^{2} / d f=1.585 ; \mathrm{CFI}=.91 ; \mathrm{TLI}=.90 ;\right.$ RMSEA .074; Hair et al. 2010).

\subsubsection{Controls}

We assessed several control variables. Age was measured in years. Tenure was measured by years of experience in the current or similar function. Gender was measured as a dichotomous variable coded as 0 for male and 1 for female. Furthermore, we included control variables for education level and organization.

\subsection{Analytical Strategy}

To examine the hypothesized mediation effects, we conducted linear multiple regression analysis by using the Hayes' PROCESS macro (Hayes 2013), which facilitates bootstrapping. A series of linear regressions (OLS) was conducted that examine the mediating effect of employee resilience on the three proactive behaviors (template 4 in PROCESS). PROCESS uses bootstrapping to overcome the drawbacks of a causal steps approach (Hayes 2009), in which a direct path is compared with a mediated path (Baron and Kenny 1986). Measures were mean-centered to eliminate some of the effects in case of multicollinearity. We checked for robustness of the model by investigating alternative specifications, such as reversing the order between mediator and outcome variables. These analyses indicated that the variance explained by alternative model specifications were less than the variance explained by our current model specification.

\section{Results}

Table 2 shows the means, standard deviations and correlations between the main variables in our study. We observe that the control variables do not structurally associate with any of the main variables, as all correlations are below .3. Hence, to increase the power of our 


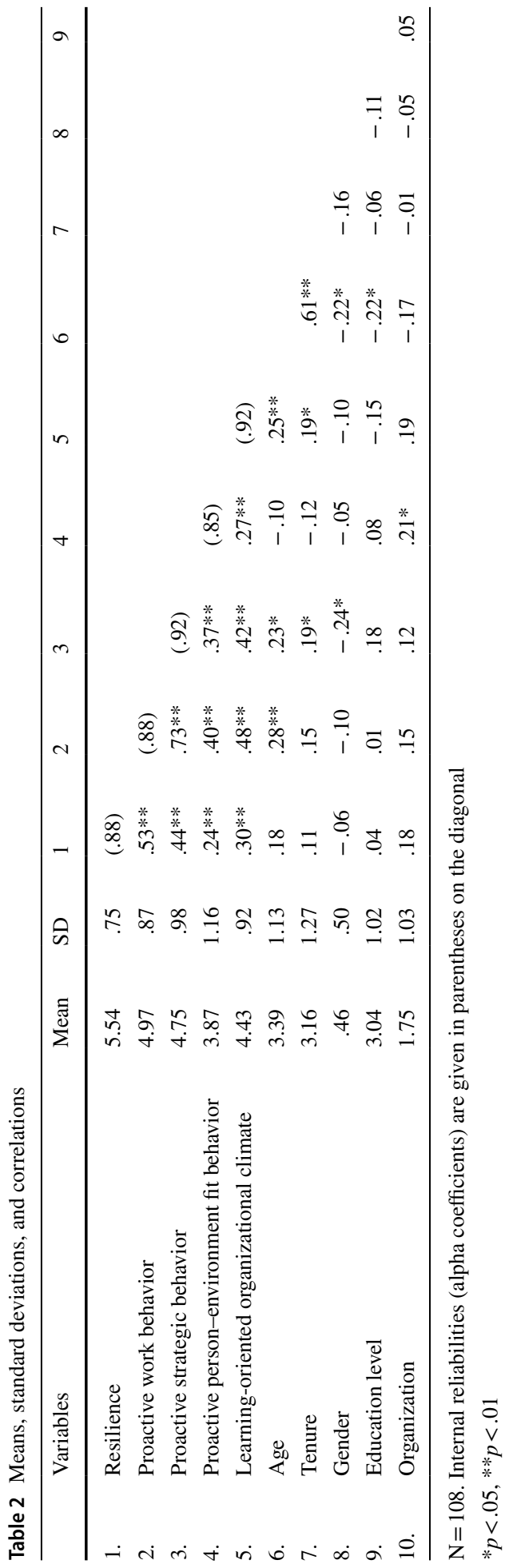




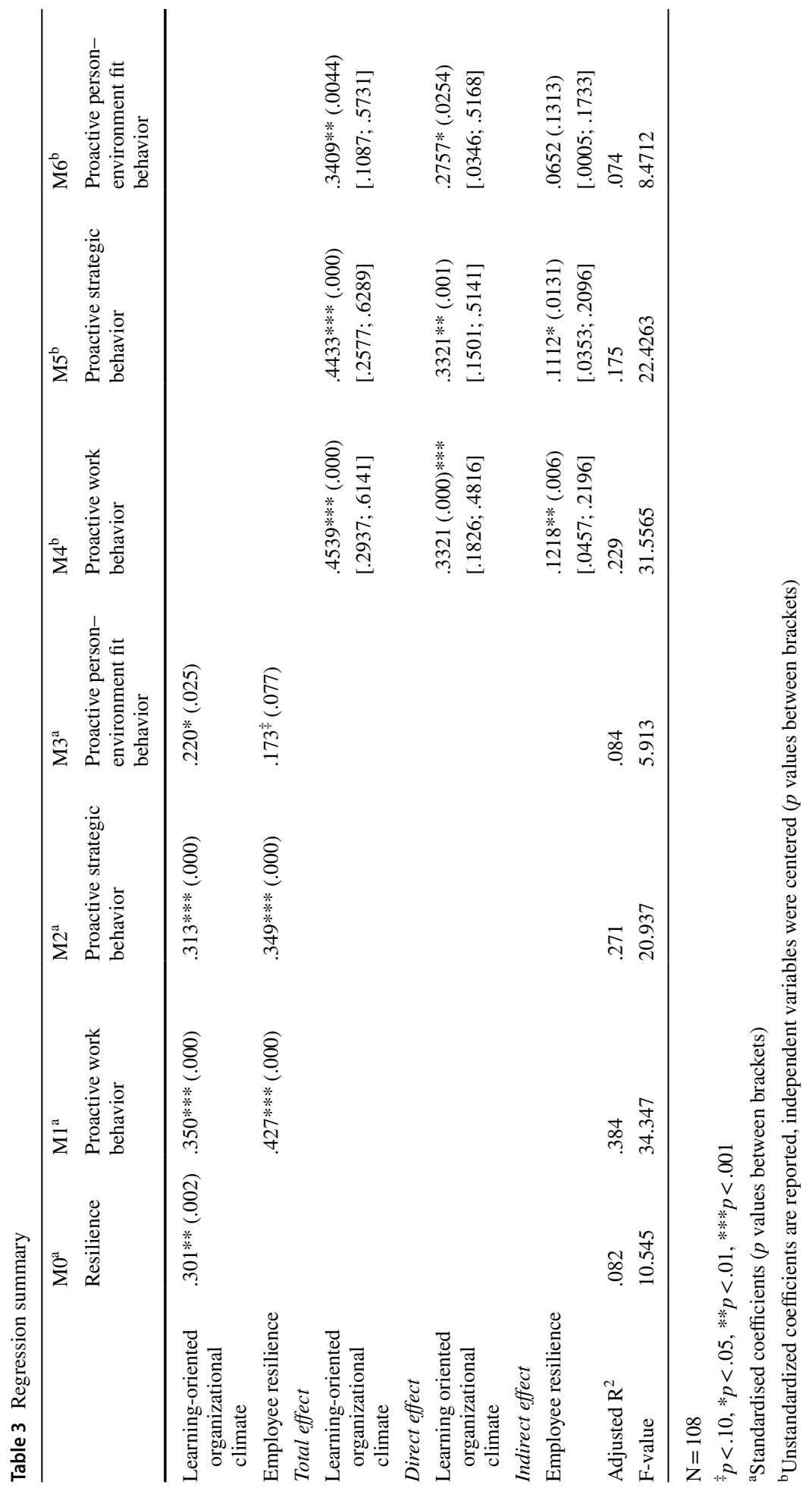




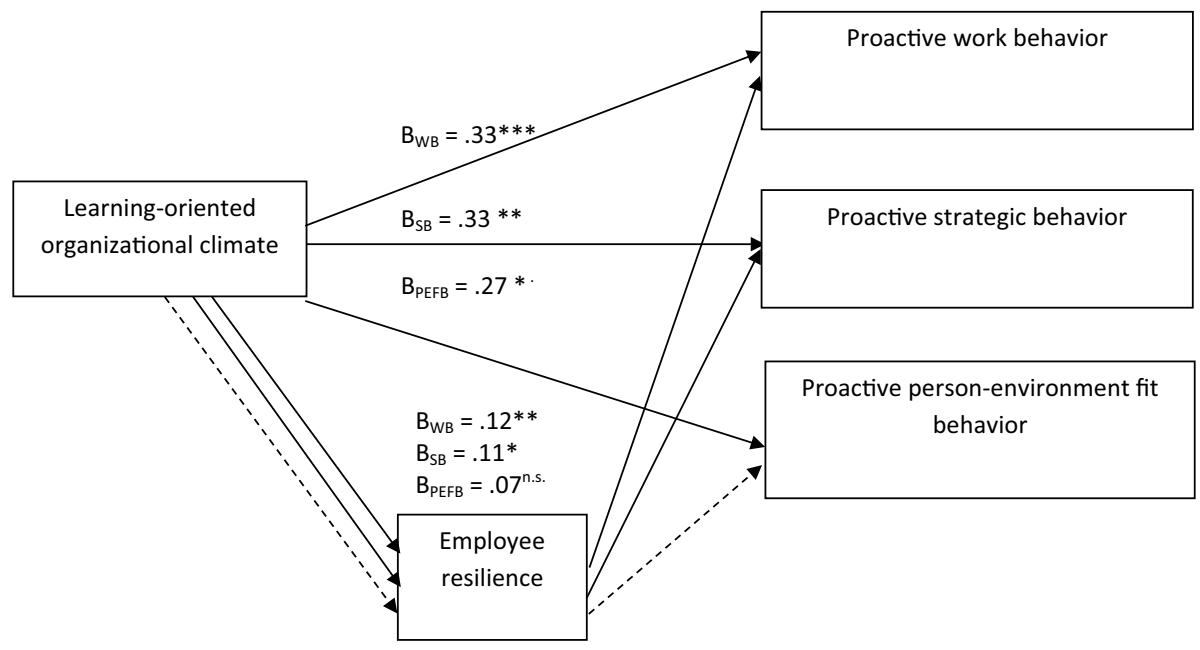

Fig. 1 Results for the hypothesized model

tests, we have left the control variables out of the regression analyses (Becker 2005). As expected, we find medium to strong correlations between different proactive behaviors.

Table 2 shows that the perception of a learning-oriented organizational climate is positively and significantly related to employee resilience. A linear regression analysis (Table 3, M0) confirms this finding, thereby supporting Hypothesis 1.

Table 3 shows that employee resilience is positively related to each of the three proactive behaviors (M1, M2, M3), thereby supporting Hypotheses 2a, 2b, and 2c. The mediations are modelled in M4, M5 and M6. We find that the total effect of each mediation model is significant $(p<.01)$. The $95 \%$ bias-corrected confidence interval (CI) for the total effects (derived from 1000 bootstrap samples) did not contain zero for any of the proposed models (M1, M2, M3). Furthermore, the analysis showed a positive significant indirect effect of resilience on proactive work behavior $(b=.122, p<.01, \mathrm{CI}=[.0457 ; .2196])$ and on proactive strategic behavior $(\mathrm{b}=.111, p<.05, \mathrm{CI}=[.0353 ; .2096])$, but not on proactive person environment fit behavior $(b=.065, p=.131, \mathrm{CI}=[.0005 ; .1733])$. This pattern of results is consistent with partial mediating effects of resilience in the relationship between a learning-oriented organizational climate and proactive work behavior, as well as proactive strategic behavior. Figure 1 summarizes the results for our hypothesized model.

\section{Discussion}

This study investigated whether and how employee resilience mediates the relationship between organizational learning and three broad categories of proactive behaviors. Learning from failure is a relevant performance-enhancing strategy (Madsen and Desai 2010; Kim et al. 2013). Prior studies have related a learning-oriented organizational climate to firm performance (van Dyck et al. 2005; Madsen and Desai 2010) and individual performance (Heimbeck et al. 2003). We add to these studies by showing the role of a learning-oriented organizational climate for employee resilience and in turn for proactive behaviors. We found that resilience mediates the relationship between a learning-oriented 
organizational climate and proactive work and proactive strategic behaviors. In contrast to our expectations, no mediating effect was found of resilience for proactive environment fit behavior.

\subsection{Theoretical Contribution}

This study extends current knowledge about organizational learning, resilience and proactivity in several ways. First, whereas previous studies have shown a direct positive relationship between a learning-oriented organizational climate and well-being at work (e.g. Van Der Heijden et al. 2009) or individual task performance (Heimbeck et al. 2003), our study is one of the first to identify its relationship with employee individual resilience. Study into this topic is of key importance, because resilience can help employees to recover after failure (Britt et al. 2016), which may be part of daily practice in innovative organizations. By addressing factors that are related to resilience, we answer the call for more understanding of resilience in the context of organizational behavior (Britt et al. 2016; Kossek and Perrigino 2016; Rothstein et al. 2016).

Second, our study is the first which identifies employee resilience as a mechanism which relates a learning-oriented organizational climate to proactive work and strategic behaviors. Employee resilience, and hence the capability to exercise some measure of adaptation in the face of taxing circumstances, promotes proactive work and proactive strategic behaviors. This finding is in line with social cognitive theory and empirical studies that found a positive relationship between the ability to recover from stressful events and the perceived amount of control over life (Benight and Bandura 2004).

Third, we add to the literature that investigates how organizations can encourage employees to engage in proactive work behaviors (e.g. Den Hartog and Belschak 2012; Zhou and George 2001). Our results demonstrate a positive relationship between a learning-oriented organizational climate and proactive work behaviors, such as taking charge, preventing problems and express voice. These results are consistent with work of Nembhard and Edmondson (2006), who show that people are more willing to speak up and take charge about an error if they do not fear negative consequences of their proactive behavior. Our empirical findings are in line with, and add to, studies that advocate the beneficial organizational outcomes of a culture characterized by openness to new ideas, and an unjudgemental assessment of contributions of employees (Zhou and George 2001), and the importance of psychological safety (Edmondson 1999) and participative safety (Anderson and West 1998). Specifically, our findings suggest that in a learning-oriented organizational climate (as opposed to a non-learning climate) employees will experiment more, take charge more often, express voice and innovate frequently, as they are not afraid for organizational repercussions for failure. With undertaking more trial and error, employees get accustomed to the fact that a large part of plans fails to work out in the desired way. Employees will expect setbacks and are hence less prone to negative emotions that are often associated with failure (Zhao 2011; Frese and Keith 2015). This continuous experience will internalize into the ability to accept setbacks and hence the ability to be resilient.

Fourth, our study suggests that by exposing resiliency, employees may predominantly increase their proactive work behaviors and strategic behaviors, and less their person-environment fit behaviors. By addressing multiple related proactive behaviors within one study design, we answered the call for research that identifies the key drivers of particular outcomes (Parker and Collins 2010; Tornau and Frese 2013). Our results suggest that employee resilience plays a key role in stimulating individual's proactive behaviors in 
the form of, for example, improving work methods, influencing work colleagues, or champion ideas to others. In doing so, we highlight that resilience actively stimulates employees to take control of and bring about change within the internal organizational environment. Moreover, we find a clear distinction between different proactivity behaviors in how their relationship with a learning-oriented organizational climate is mediated by employee resilience. Contrary to what was expected, a comparison of multiple proactive behavior constructs indicates that employee resilience is not positively associated with engaging in proactive person-environment fit behavior. Apparently the way how employees manage their careers proactively is not stimulated by a learning-oriented organizational climate and employee resilience. A possible explanation for this finding could be that proactive work and strategic behaviors include behaviors that are explicitly targeted at improving daily work practices and long term organizational improvement, instead of person-organization fit. In a learning-oriented organizational learning climate, this particular set of proactive behaviors addresses daily practices and overall improvement, and therefore is stimulated by individual resilience to setbacks during innovation projects.

\subsection{Recommendations for Practice}

Our study has implications for managerial practice. Our finding supports a mediating effect of employee resilience in the relationship between a learning-oriented organizational climate and proactive work and proactive strategic behaviors. Organizational management is therefore advised to actively stimulate employee resilience, for example by designing supportive cultures within the organization that provide room for learning from trial and error (Frese and Fay 2001). Furthermore, interventions aimed at the development of resilient behavior could be particularly suitable (Strauss and Parker 2015). Human resource practices can be employed that are oriented at developing and nurturing employee resilience. In this respect, coaching and mentoring trajectories could be offered to employees (Verbruggen et al. 2007).

\subsection{Limitations and Future Research}

This study has several limitations. The cross-sectional design of the study harbors cautiousness with interpreting the findings with respect to antecedents, as our data does not allow for drawing conclusions about causality. Although other studies have shown the causality between a learning-oriented organizational climate and proactivity-related behavior (e.g. Den Hartog and Belschak 2012), as well as between proactivity and organizational outcomes, such as well-being (e.g. Van Der Heijden et al. 2009), longitudinal studies are warranted to unravel the effects of relevant variables on the hypothesized relationships. Relatedly, using cross-sectional data to test a mediation model requires a strong theoretical underpinning of the proposed relationships. Therefore, we investigated a model in which relationships were reversed, i.e. a model in which the three proactive behaviors were mediating the relationship between a learning-oriented organizational climate and employee resilience. The results indicated that the variance explained by such a model was much less than the variance explained by our model specification. Hence, we assume that our model specification is warranted. Nevertheless, longitudinal research is needed to test this assumption. In this respect, it would also be interesting to test for cross-lagging effect to explore whether the enactment of proactive behaviors and the capacity to bounce back from challenges are mutually-enhancing. 
Furthermore, although we can justify the use of self-reports for measuring individual resilience, future research may want to add independent ratings of resilience to selfreported data in order to avoid dependence on single source data. For example, with respect to resilience, spouse ratings could be used. Spouses may be very apt in assessing their partners' resilience. When external raters know the target respondent well, as is likely to be the case for spouses, informant reports can provide substantial improvements over self-reports in predicting a variety of variables, especially variables related to social desirable behavior or traits (Smith and Williams 2016; Connelly and Ones 2010; Vazire and Carlson 2011). Additional research would be needed to assess whether spouse-rated scores can sufficiently capture individual resilience in an objective way (Frese and Zapf 1999; Parker and Collins 2010).

Another limitation is the use of the scale by Von Eisenhart Rothe et al. (2013). Recently, other scales have become available that may better capture the ongoing development of employees beyond the ability to bounce back (Näswall et al. 2015). In hindsight such a scale may have been more suitable for the purpose of this study. Therefore, for future research we encourage scholars to use a resilience scale that explicitly takes into account a work context and includes developmental aspects. Our study would benefit from a replication with another resilience scale.

Finally, future research may want to include other variables into a model that relates a learning-oriented organizational climate to employee resilience. For instance, specific personality traits may moderate the relationships that were hypothesized in our model. For example, Naveh et al. (2015) demonstrated the relationship between an active learning climate and the error rates of different personality types. Following this line of thought, it may be that individuals with a high openness to experience more easily display proactive behavior than individuals that score low on this character trait. Similarly, individuals who have a high level of conscientiousness may be less likely to display proactive behavior than individuals that score low on this character trait. Proactive employees show high degrees of rule breaking (Belschak and Den Hartog 2010), which is likely to be out of the comfort zone of conscientious individuals. Future research may look into these factors and investigate how they influence the results from our study.

Despite these limitations, examining the relationship between a learning-oriented organizational climate, employee resilience, and proactive behaviors is useful for further refining our understanding of the mechanisms that enhance self-management behaviors at work.

Acknowledgements An earlier draft of this paper was presented at the PDMA Annual Research Forum in Chicago (November 2017) and the R\&D management conference in Milan (July 2018).

Open Access This article is distributed under the terms of the Creative Commons Attribution 4.0 International License (http://creativecommons.org/licenses/by/4.0/), which permits unrestricted use, distribution, and reproduction in any medium, provided you give appropriate credit to the original author(s) and the source, provide a link to the Creative Commons license, and indicate if changes were made.

\section{References}

Anderson, N. R., \& West, M. A. (1998). Measuring climate for work group innovation. Journal of Organizational Behavior. https://doi.org/10.1002/(SICI)1099-1379(199805)19:3\%3c235:AID-JOB83 7\%3e3.0.CO;2-C.

Ashford, S. J., \& Cummings, L. L. (1983). Feedback as an individual resource: Personal strategies of creating information. Organizational Behavior and Human Performance, 32(3), 370-398. https://doi. org/10.1016/0030-5073(83)90156-3. 
Ashford, S. J., Rothbard, N. P., Piderit, S. K., \& Dutton, J. E. (1998). Out on a limb: The role of context and impression management in selling gender-equity issues. Administrative Science Quarterly. https://doi. org/10.2307/2393590.

Baer, M., \& Frese, M. (2003). Innovation is not enough. Journal of Organizational Behavior, 24, 45-68. https://doi.org/10.1002/job.179.

Bandura, A. (1986). Social foundations of thought and action: A social cognitive theory. Englewood Cliffs, NJ: Prentice-Hall. https://doi.org/10.1146/annurev.psych.52.1.1.

Baron, R. M., \& Kenny, D. A. (1986). The moderator-mediator variable distinction in social psychological research. Journal of Personality and Social Psychology, 51(6), 1173. https://doi. org/10.1037/0022-3514.51.6.1173.

Becker, T. E. (2005). Potential problems in statistical control of variables in organizational research. Organizational Research Methods, 8, 274-289. https://doi.org/10.1177/1094428105278021.

Belschak, F. D., \& Den Hartog, D. N. (2010). Pro-self, prosocial, and pro-organizational foci of proactive behaviour. Journal of Occupational and Organizational Psychology, 83, 475-498. https://doi. org/10.1348/096317909X439208.

Benight, C. C., \& Bandura, A. (2004). Social cognitive theory of posttraumatic recovery. Behaviour Research and Therapy, 42, 1129-1148.

Bhamra, R., Dani, S., \& Burnard, K. (2011). Resilience: The concept, a literature review and future directions. International Journal of Production Research, 49(18), 5375-5393. https://doi.org/10.1080/00207 543.2011.563826

Bindl, U. K., \& Parker, S. K. (2010). Proactive work behavior: Forward-thinking and changeoriented action in organizations. In S. Zedeck (Ed.), APA handbook of industrial and organizational psychology. Washington, DC: American Psychological Association. https://doi.org/10.1037/12170-019.

Britt, T. W., Shen, W., Sinclair, R. R., Grossman, M. R., \& Klieger, D. M. (2016). How much do we really know about employee resilience? Industrial and Organizational Psychology, 9(2), 378-404. https:// doi.org/10.1017/iop.2015.107.

Chiaburu, D. S., Baker, V. L., \& Pitariu, A. H. (2006). Beyond being proactive: What (else) matters for career self-management behaviors? Career Development International, 11(7), 619-632. https://doi. org/10.1108/13620430610713481.

Connelly, B. S., \& Ones, D. S. (2010). An other perspective on personality: Meta-analytic integration of observers' accuracy and predictive validity. Psychological Bulletin, 136, 1092-1122. https://doi. org/10.1037/a0021212.

Conway, J. M., \& Lance, C. E. (2010). What reviewers should expect from authors regarding common method bias in organizational research. Journal of Business and Psychology, 25(3), 325-334. https:// doi.org/10.1007/s10869-010-9181-6.

Coutu, D. L. (2002). How resilience works. Harvard Business Review, 80(5), 46-56.

Den Hartog, D. N., \& Belschak, F. D. (2012). When does transformational leadership enhance employee proactive behavior? Journal of Applied Psychology, 97(1), 194. https://doi.org/10.1037/a0024903.

Dillman, Don A. (2000). Mail and internet surveys: The tailored design method (2nd ed.). New York: Wiley.

Edmondson, A. (1999). Psychological safety and learning behavior in work teams. Administrative Science Quarterly, 44(2), 350-383. https://doi.org/10.2307/2666999.

Frese, M., \& Fay, D. (2001). Personal initiative: An active performance concept for work in the 21 st century. Research in Organizational Behavior, 23, 133-187. https://doi.org/10.1016/S0191-3085(01)23005-6.

Frese, M., \& Keith, N. (2015). Action errors, error management, and learning in organizations. Annual Review of Psychology, 66, 661-687. https://doi.org/10.1146/annurev-psych-010814-015205.

Frese, M., \& Zapf, D. (1999). On the importance of the objective environment in stress and attribution theory. Journal of Organizational Behavior. https://doi.org/10.1002/(SICI)1099-1379(19990 9)20:5\%3c761:AID-JOB951\%3e3.0.CO;2-Y.

Grant, A. M., \& Ashford, S. J. (2008). The dynamics of proactivity at work. In B. M. Staw \& A. P. Brief (Eds.), Research in organizational behavior (Vol. 28, pp. 3-34). New York: Elsevier. https://doi. org/10.1016/j.riob.2008.04.002.

Griffin, M. A. (2007). Specifying organizational contexts: Systematic links between contexts and processes in organizational behavior. Journal of Organizational Behavior, 28(7), 859-863. https://doi. org/10.1002/job.489.

Griffin, M. A., Neal, A., \& Parker, S. K. (2007). A new model of work role performance: Positive behavior in uncertain and interdependent contexts. Academy of Management Journal, 50(2), 327-347.

Hair, J. F., Black, W. C., Babin, B. J., \& Anderson, R. E. (2010). Multivariate data analysis (7th ed.). Upper Saddle River, NJ: Prentice Hall.

Hayes, A. F. (2009). Beyond Baron and Kenny: Statistical mediation analysis in the new millennium. Communication Monographs, 76(4), 408-420. https://doi.org/10.1080/03637750903310360. 
Hayes, A. F. (2013). Introduction to mediation, moderation, and conditional process analysis. New York: Guilford Press.

Heimbeck, D., Frese, M., Sonnentag, S., \& Keith, N. (2003). Integrating errors into the training process. Personnel Psychology, 56, 333-362. https://doi.org/10.1111/j.1744-6570.2003.tb00153.x.

Hirst, G., Van Knippenberg, D., \& Zhou, J. (2009). A cross-level perspective on employee creativity. Academy of Management Journal, 52(2), 280-293. https://doi.org/10.5465/AMJ.2009.37308035.

Huang, L., \& Luthans, F. (2015). Toward better understanding of the learning goal orientation-creativity relationship. Applied Psychology, 64(2), 444-472. https://doi.org/10.1111/apps.12028.

Kim, S., Egon, T. M., Kim, W., \& Kim, J. (2013). The impact of managerial coaching behavior on employee work-related reactions. Journal of Business and Psychology, 28, 315-330. https://doi.org/10.1007/ s10869-013-9286-9.

Kossek, E. E., \& Perrigino, M. B. (2016). Resilience: A review using grounded integrated occupational approach. The Academy of Management Annals, 10(1), 729-797.

Kuntz, J., Connell, P., \& Näswall, K. (2017a). Workplace resources and employee resilience. Career Development International, 22(4), 419-435. https://doi.org/10.1108/CDI-11-2016-0208.

Kuntz, J., Malinen, S., \& Näswall, K. (2017b). Employee resilience: Directions for resilience development. Consulting Psychology Journal, 69(3), 223-242.

Lance, C. E., LaPointe, J. A., \& Fisicaro, S. A. (1994). Test of three causal models of halo rater error. Organizational Behavior and Human Decision Processes, 57, 83-96. https://doi.org/10.1006/ obhd.1994.1005.

Liu, W., Tangirala, S., Lee, C., \& Parker, S. K. (2016). Exploring the consequences of proactive behaviors. Journal of Organizational Behavior, 24, 1-11.

London, M. (1993). Relationship between career motivation, empowerment and support for career development. Journal of Occupational and Organizational Psychology, 66, 55-69.

Luthans, F. (2002). Positive organizational behavior. Developing and managing psychological strengths. Academy of Management Executive, 16(1), 57-72.

Mache, S., Vitzthum, K., Klapp, B. F., \& Danzer, G. (2014). Surgeons' work engagement: Influencing factors and relations to job and life satisfaction. The Surgeon, 12(4), 181-190.

Madsen, P. M., \& Desai, V. M. (2010). Failing to learn? The effect of failure and successes on organizational learning the global orbital launch vehicle industry. Academy of Management Journal, 53(3), 451-476.

Malhotra, N. K., Kim, S. S., \& Patil, A. (2006). Common method variance in IS research. Management Science, 52(12), 1865-1883. https://doi.org/10.1287/mnsc.1060.0597.

Meneghel, I., Salanova, M., \& Martínez, I. M. (2016). Feeling good makes us stronger. Journal of Happiness Studies, 17(1), 239-255. https://doi.org/10.1007/s10902-014-9592-6.

Morrison, E. W., \& Phelps, C. C. (1999). Taking charge at work. Academy of Management Journal, 42(4), 403-419. https://doi.org/10.2307/257011.

Näswall, K., Kuntz, J., Hodliffe, M., \& Malinen, S. (2015). Employee resilience scale (EmpRes). Resilient Organisations Research Report 2013/06. Christchurch, New Zealand: University of Canterbury.

Naveh, E., Katz-Navon, T., \& Stern, Z. (2015). Active learning climate and employee errors. Journal of Organizational Behavior, 36(3), 441-459. https://doi.org/10.1002/job.2000.

Nembhard, I. M., \& Edmondson, A. C. (2006). Making it safe: The effects of leader inclusiveness and professional status on psychological safety and improvement efforts in health care teams. Journal of Organizational Behavior, 27, 941-966. https://doi.org/10.1002/job.413.

Parker, S. K., \& Collins, C. G. (2010). Taking stock: Integrating and differentiating multiple proactive behaviors. Journal of Management, 36(3), 633-662. https://doi.org/10.1177/0149206308321554.

Podsakoff, P. M., MacKenzie, S. B., Lee, J. Y., \& Podsakoff, N. P. (2003). Common method biases in behavioural research. Journal of Applied Psychology, 88(5), 879-903. https://doi. org/10.1037/0021-9010.88.5.879.

Putz, D., Schilling, J., Kluge, A., \& Stangenberg, C. (2012). Measuring organizational learning from errors. Management Learning, 44(5), 511-536. https://doi.org/10.1177/1350507612444391.

Rothstein, M. G., McLarnon, M. J. W., \& King, G. (2016). The role of self-regulation in workplace resiliency. Industrial and Organizational Psychology, 9(2), 416-421.

Scott, S. G., \& Bruce, R. A. (1994). Determinants of innovative behavior. Academy of Management Journal, 37(3), 580-607. https://doi.org/10.2307/256701.

Simonton, D. K. (1984). Genius, creativity, and leadership. Boston, MA: Harvard University Press.

Sitkin, S. B. (1992). Learning through failure: The strategy of small losses. Research in Organizational Behavior, 14, 231-266.

Smith, B. W., Dalen, J., Wiggins, K., Tooley, E., Christopher, P., \& Bernard, P. (2008). The brief resilience scale: Assessing the ability to bounce back. International Journal of Behavioral Medicine, 15, 194200. https://doi.org/10.1080/10705500802222972. 
Smith, T. W., \& Williams, P. G. (2016). Assessment of social traits in married couples: Self-reports versus spouse ratings around the interpersonal circumplex. Psychological Assessment, 28(6), 726-736.

Spector, P. E. (2006). Method variance in organizational research. Organizational Research Methods, 9(2), 221-232. https://doi.org/10.1177/1094428105284955.

Strauss, K., \& Parker, S. K. (2015). Intervening to enhance proactivity in organizations. Journal of Management, $X X(\mathrm{X}), 1-29$. https://doi.org/10.1177/0149206315602531.

Sutcliffe, K. M., \& Vogus, T. J. (2003). Organizing for resilience. In K. S. Cameron, J. E. Dutton, \& R. E. Quinn (Eds.), Positive organizational scholarship: Foundations of a new discipline (pp. 94-110). San Francisco, CA: Berrett-Koehler.

Tesluk, P. E., Farr, J. L., \& Klein, S. R. (1997). Influences of organizational culture and climate on individual creativity. The Journal of Creative Behavior, 31, 27-41. https://doi.org/10.1002/j.2162-6057.1997. tb00779.x.

Tornau, K., \& Frese, M. (2013). Construct clean-up in proactivity research. Applied Psychology, 62(1), 44-96. https://doi.org/10.1111/j.1464-0597.2012.00514.x.

Van Der Heijden, B., Boon, J., Van der Klink, M., \& Meijs, E. (2009). Employability enhancement through formal and informal learning. International Journal of Training and Development, 13(1), 19-37. https ://doi.org/10.1111/j.1468-2419.2008.00313.x.

Van Dyck, C., Frese, M., Baer, M., \& Sonnentag, S. (2005). Organizational error management culture and its impact on performance. Journal of Applied Psychology, 90(6), 1228. https://doi. org/10.1037/0021-9010.90.6.1228.

Van Dyne, L., \& LePine, J. A. (1998). Helping and voice extra-role behaviors. Academy of Management Journal, 41(1), 108-119. https://doi.org/10.2307/256902.

Vazire, S., \& Carlson, E. N. (2011). Others sometimes know us better than we know ourselves. Current Directions in Psychological Science, 20, 104-108. https://doi.org/10.1177/0963721411402478.

Verbruggen, M., Sels, L., \& Forrier, A. (2007). Unraveling the relationship between organizational career management and the need for external career counseling. Journal of Vocational Behavior, 71(1), 69-83.

Vogus, T. J., \& Sutcliffe, K. M. (2007, October). Organizational resilience: Towards a theory and research agenda. In 2007. ISIC. IEEE international conference on systems, man and cybernetics (pp. 34183422). IEEE. https://doi.org/10.1109/icsmc.2007.4414160.

Von Eisenhart Rothe, A., Zenger, M., Lacruz, M. E., Emeny, R., Baumert, J., Haefner, S., et al. (2013). Validation and development of a shorter version of the resilience scale RS-11. BMC Psychology, 1(1), 1-25. https://doi.org/10.1186/2050-7283-1-25.

Wagnild, G., \& Young, H. (1993). Development and psychometric evaluation of resilience scale. Journal of Nursing Measurement, 1(2), 165-178.

Wang, Z., Li, C., \& Li, X. (2017). Resilience, leadership and work engagement: The mediating role of positive affect. Social Indicators Research, 132, 699-708. https://doi.org/10.1007/s11205-016-1306-5.

Xanthopoulou, D., Bakker, A. B., Demerouti, E., \& Schaufeli, W. B. (2009). Reciprocal relationships between job resources, personal resources, and work engagement. Journal of Vocational Behavior, 74, 235-244.

Youssef, C. M., \& Luthans, F. (2007). Positive organizational behavior in the workplace. Journal of Management, 33(5), 774-800. https://doi.org/10.1177/0149206307305562.

Zhao, B. (2011). Learning from errors: The role of context, emotion, and personality. Journal of Organizational Behavior, 32, 435-463. https://doi.org/10.1002/job.696.

Zhou, J., \& George, J. M. (2001). When job dissatisfaction leads to creativity. Academy of Management Journal, 44(4), 682-696. https://doi.org/10.2307/3069410. 